\title{
Letter in response to article: \\ Incidence pattern and spatial analysis of breast cancer in Iranian women: geographical Information system applications
}

Ahmadi A; Ramazani R; Rezagholi T; Yavari P. Incidence pattern and spatial analysis of breast cancer in Iranian women: Geographical Information System applications. East Mediterr Health J. 2018;24(4):360-367. https://doi.org/10.26719/2018.24.4.360

\section{Methodological note on spatial classification}

\author{
Amin Radmanesh, ${ }^{1,2}$ Mohamad Amin Pourhoseingholi ${ }^{3}$ and Meysam Olfatifar ${ }^{3,4}$ \\ ${ }^{1}$ Legal Medicine Research Center, Legal Medicine Organization, Tehran, Islamic Republic of Iran. ${ }^{2}$ Department of Tissue Engineering and Applied Cell \\ Sciences, Shahid Beheshti University of Medical Sciences, Tehran, Islamic Republic of Iran. ${ }^{3}$ Gastroenterology and Liver Diseases Research Center, \\ Research Institute for Gastroenterology and Liver Diseases, Shahid Beheshti University of Medical Sciences, Tehran, Islamic Republic of Iran. ${ }^{4}$ Basic \\ and Molecular Epidemiology of Gastrointestinal Disorders Research Center, Research Institute for Gastroenterology and Liver Diseases, Shahid \\ Beheshti University of Medical Sciences, Tehran, Islamic Republic of Iran. (Correspondence to: Meysam Olfatifar: ol.meysam92@gmail.com).
}

Citation: Radmanesh A; Pourhoseingholi MA; Olfatifar M. Methodological note on spatial classification. East Mediterr Health J. 2019;25(3):218 https:// doi.org/10.26719/2019.25.3.218

Received: 18/07/18; accepted: 28/03/19

Copyright @ W World Health Organization (WHO) 2019. Some rights reserved. This work is available under the CC BY-NC-SA 3.o IGO license (https:// creativecommons.org/licenses/by-nc-sa/3.o/igo).

Sir,

We read with interest the recent paper by Ali Ahmadi et al. (1). We appreciate the authors of this valuable work for their contribution to knowledge in the field of breast cancer. They first calculated crude incidence rates for each province then used the World Health Organization (WHO) standard population to estimate Standardized Incidence Rates (ASR). Finally, they tried to perform a spatial analysis to determine the incidence pattern of breast cancer in the Islamic Republic of Iran. The mean ( \pm standard deviation or SD) age of patients was 50.9 (12.6) years. There was a clustering pattern in ASR of Mazandaran, Tehran, Alborz, Isfahan and Markazi Provinces and a significant cluster of high incidence rates of breast cancer in Iranian women.

After reading this paper we think it worthwhile to note some important methodological issues to prevent misinterpretation and misleading messages. But before anything, it should be noted that this study is not the first that attempts to examine the clustering of breast cancer incidences in the Islamic Republic of Iran, as mentioned by the authors in the discussion $(2,3)$. First, the authors may have been mistaken in their use of clustering techniques, reporting the results of the global Moran I index (a spatial autocorrelation index that assigns an amount between -1 to +1 to all studied units [provinces], merely to rule out the spatial randomness and not mapping the studied units, as mentioned in this study Moran's index $=0.579, P<0.001$, Figure 2) as local Moran (used to deal with multiple spatial relationship between units and mapping the studies units in four classes) (2). Second, surely the authors have been mistaken in their reporting of the Getis-Ord test results as local indicators of spatial autocorrelation (LISA) index; as mentioned, the local Moran classify the studied units in four classes and do not map units in the form of $\pm S D$. Third, the following sentence by the authors is ambiguous, "we selected Conceptualization of Spatial Relationships (CSR) from the spatial statistic tools", because CSR is an option for calculating clustering patterns and reflect the inherent relationship between units of study, and its exact determination is very important. Finally, the authors have probably been mistaken in accurately determining the distance band (a positive number representing a cutoff point that the blocks or provinces outside of which are not considered in calculating spatial clusters), because they report two different results for Getis-Ord index (Figures 2 and 3). It should be noted that the exact determination of the distance band can change the results of the study. In conclusion, readers are strongly suggested to consider the aforementioned comments and necessity for reanalysis to avoid misclassification and misinterpretation.

\section{References}

1. Ahmadi A, Ramazani R, Rezagholi T, Yavari P. Incidence pattern and spatial analysis of breast cancer in Iranian women: Geographical Information System applications. East Mediterr Health J. 367-360:(4)24;2018. https://doi.org/2018.24.4.360/10.26719

2. Olfatifar M, Karami M, Moghimbeigi A, Motlagh A, Rooshanaee G, et al. Spatial clustering of breast cancer: an epidemiological analysis of Iranian women, Int J Cancer Manag. 1)10 ; 2017):e5402. doi: 10.17795/ijcp5402-.

3. Ayubi E, Mansournia MA, Motlagh AG, Mosavi-Jarrahi A, Hosseini A, Yazdani K. Exploring neighborhood inequality in female breast cancer incidence in Tehran using Bayesian spatial models and a spatial scan statistic. Epidemiol Health. 2017 May 39;17:e2017021. https://doi.org/10.4178/epih.e2017021 